\title{
XXXIV. The description of a safety furnace for preventing explosions in coal-mines
}

\section{Robert Bakewell Esq.}

To cite this article: Robert Bakewell Esq. (1817) XXXIV. The description of a safety furnace for preventing explosions in coal-mines, Philosophical Magazine Series 1, 50:233, 211-213, DOI: $10.1080 / 14786441708637760$

To link to this article: http://dx.doi.org/10.1080/14786441708637760

里 Published online: 27 Jul 2009.

Submit your article to this journal

Џ Article views: 2 
grinciple called gravitation, by which, false analogies have been introduced into philosophy." Let us, however, in a single instance observe how these "known motions of Nature" supply the place of the "assumed principle called gravitation."

The weight of bodies, and their velocity in falling, uniform experience shows to be least at the equator, and to increase with the latitude. Now as the rotary motion of the earth's surface and atmosphere diminishes from the equator to the poles, where it ceases in both; the weight of bolies and their velocity in falling, ought, according to Sir Richard's doctrine, to be greatest al the equator, and to diminish as the latitude increases. Nay further, since there exists neither rotary motion on the earth's surface at the poles, nor in the atmosphere in its prolonged axis, a direct consequence of his doctrine is, that bodies at the poles are devoid of all weight, and when projected perpendicularly thence, they never return to the earth! I am, sir,

Bath, Sept. 9, 1817.

Your very obedient servant, F. E...s.

XXXIV. The Description of a Safety Furnace for preventing Explosions in Coal-Mines. By RoBert Bakeweld, Esq.

\section{To $M r$. Tilloch.}

DeAR SIR,- T HE attention of coal proprictors has lately been directed to the explosions which take place in mines from the lights used by the workmen; but it is well known that similar explosions are often occasioned by the inflammation of the carburetted hydrogen gas, as it passes the fire placed near the upcast shaft to rarefy the air and promote ventilation. 'The fire which is generally necessary, is thus not unfrequently the cause of the most fatal accidents.

To prevent this, no remedy has been proposed that $I$ am acquainted with, except the substitution of a charcoal fire, on the principle that the gas will not explode by a red heat burning without Hame. An open charcoal fire is, however, liable to the following objections. The carbonic acid gas generated by the combustion of charcoal being specifically heavier than the air of the mine, will, as it is cooled in its passage upwards, descend again and choak the lower part of the shaft. A particle of common coal intermixed with the charcoal, or falling into the fire, might produce flame and cause an explosion. The comparative dearness of charcoal will also tend to prevent its introduction. Colie from coal is more easily procured, but it sometimes beams O 2 
with a lambent flame sufficient to ignite explosive mixtures of gas.

A fire which will burn with perfect safety in mines, and at the same time occasion a brisk circulation of air, has been hitherto a desideratum. I am induced to believe, that I have discovered how this may be obtained by the introduction of a furnace, simple in construction, in which coke or even common coal may be burnt, without any danger, and the circulation of air in the mine greatly increased.

The furnace or stove admits of considerable variation in size and form, according to the situations in which it may be used; and as it can be erected at a small expense, I trust no prejudice can exist to prevent a fair trial of its utility. The accompanying drawing will explain its construction, and enable any coal proprietor to apply the furnace to his own use. AA a a (Plate III. fig. 1,) represent the body of the stove and chimney, which should be of cast iron in one piece without any side-door or opening whatever, as it is supplied with fuel at the mouth or chimuey. 66 represent the grate, which moves upon an hinge, and opens downwards by removing an iron peg $c$, in order to clear the grate when wanted, and $d d$ a broad rim below the grate perforated by the air-holes eee. F is a cistern of stone or brick to be fllled with water above the lower edge of the rim $d d$. The diameter of the furnace at the grate may be 30 inches, that of the chimney about 18 inches, to admit the fuel. The height of the chininey, if coke be used, need scarcely exceed ten feet, and may be inclined or not at option, according to the situation. When the furnace is lighted, which may be done by introducing lighted coke down the chimney, there will be no access of air but through the apertures $e e e$, which may be regulated at pleasure, by stops to increase or diminish the current. The use of the water-trough is to confine the admission of air to the openings $e e$, and also to prevent any accidental inflammation of coal or other substance below the grate.

Should the air of the mine be charged with inflammable gas to the explosive point, it is prevented from passing near the surface of the fire by the sides of the stove; and should even the lowest stratum of air which enters the apertures $e e$ be explosive, which can rarely occur, this air will lose a part of its oxygen by passing through the red-hot coke, and by its further admixture with carbonic acid gas confined in the stove, must cease to be inflammable. The general current of inflammable air will pass with perfect safety over the mouth of the chimney, and will ascend the shaft from the heat communicated to it by the surface of the stove. If common coal be used, a chimney of greater length 
Remarks on Objections to Experiments on Vegelation. 213

length must be joined to $a a$, reaching bevond the possible extension of the fame. To prevent inflammation at the lower part of the fire, there must be only one aperture below the grate, into which an air-pipe must be closely fitted. This must extend above the top of the pit, and be of sufficient width to admit a free passage for the air downwards to the fire. By this means the remotest possibility of danger would be avoided either from a coke or a coal fire; the rarefaction of the air would be dependent on the heated surface of the stove.

I have ascertained by experiment, that a small current of pure hydrogen gas will inflame at the distance of nearly two inches above the apex of a newly-snuffed candle, but will not inflame when passed over the chimney of a lamp where paper would be scorched without ignition. We may by this means have a metre of the length of chimney necessary to prevent the inflanmation of gas, according as the materials burned may evolve more or less flame.

Where the apertures $e e$ are used without the air-pipe, they may be covered with double wire-gituze, which might prevent any inflammation under the grate communicating with the air of the mine. With these precautions one or more fires might be constantly burning near the upcast shaft, and by increasing the quantity of heated surface, we may accelerate the ascent of air more rapidly than by an open fire as at present used.

So long as the fire continues to burn, the air in the mine will never pass down the chimney or reach the fire from above; and were the hydrogen to inflame when the air is admitted through the apertures $e e$; if they are clothed with wire-gauze, the flame will be confined to the under part of the grate, and may be in stantly extinguished by closing the apertures.

The simplicity of this safety furnace will, J trust, recommend it to the early notice of coal proprietors; and should it be found to lessen the dangers to which the workmen in mines are exposed, my object in this communication to your valuable publication will be fully answered.

I am, dear sir, yours, sic.

13, Tavistock Strect, Pedford square,

Robt. BAKEwell. Sept. 5, 1817.

XXXV. Remarks on Mr. Murnay's Oljections to Experiments on Vegetation detailed in the Phil. Mag. for July last. By Mr. J. Tatum.

$$
\text { To Mr. Tilloch. }
$$

$S_{I R},-Y_{\text {oun }}$ correspondent Mr. Murray has, in your last Number, objected not only to the manner in which $l$ conducted O 3 the 